\title{
Internal iliac artery sacrifice during endovascular abdominal aortic aneurysm repair
}

\author{
Baker Ghoneim ${ }^{1,2}$, Patrick Canning', Yogesh Acharya ${ }^{1,2}$, Niamh Hynes $^{3}$, Wael Tawfick¹, Sherif Sultan ${ }^{1,3}$ \\ 'Western Vascular Institute, Department of Vascular and Endovascular Surgery, Galway University Hospital, National University \\ of Ireland, Galway H91 YR71, Ireland. \\ ${ }^{2}$ Department of Vascular Surgery, Faculty of Medicine, Cairo University, Cairo 12613, Egypt. \\ ${ }^{3}$ Galway Clinic, Department of Vascular and Endovascular Surgery, Doughiska, Galway H91HHTO, Ireland.
}

Correspondence to: Prof. Sherif Sultan, MCh, MD, FRCS, FACS, PhD. Department of Vascular and Endovascular Surgery, Western Vascular Institute, National University of Ireland, Newcastle Road, Galway, Ireland H91 YR71.

E-mail: sherif.sultan@hse.ie; sherif.sultan@nuigalway.ie. ORCID: 0000-0001-8767-4929.

How to cite this article: Ghoneim B, Canning P, Acharya Y, Hynes N, Tawfick W, Sultan S. Internal iliac artery sacrifice during endovascular abdominal aortic aneurysm repair. Vessel Plus 2020;4:38. http://dx.doi.org/10.20517/2574-1209.2020.35

Received: 28 Jul 2020 First Decision: 8 Aug 2020 Revised: 3 Nov 2020 Accepted: 17 Nov 2020 Published: 10 Dec 2020

Academic Editor: Junmin Zhu Copy Editor: Cai-Hong Wang Production Editor: Jing Yu

\begin{abstract}
Aim: We aimed to assess the clinical outcomes of the internal iliac artery (IIA) coverage during endovascular abdominal aortic aneurysm repair (EVAR).
\end{abstract}

Methods: A retrospective observational study was conducted in patients managed with EVAR for the aorto-iliac aneurysmal disease. The IIA was sacrificed by extension of the stent-graft into the external iliac artery in the absence of the distal landing zone, while it was preserved if the landing zone was available.

Results: From 2002 to 2018, 540 patients underwent EVAR for aorto-iliac aneurysmal disease in our center. Sixtyfive $(12.04 \%, n=65 / 540)$ had iliac aneurysm extension. Among these 65 cases, the IIA was not covered in 32 patients (IIA salvage/spared group), while they were covered in 33 patients (IIA sacrifice group). The IIA sacrifice group consisted of 25 unilateral and 8 bilateral coverages. There was $100 \%$ technical success and no 30 -day mortality in both groups. The IIA sacrifice group had more postoperative complications in general when compared to the IIA salvage group, but they were not significant $(P<0.05)$. There were one patient with buttock claudication $(P=1.000)$ with bilateral IIA coverage, two cases of lower limb microembolization $(P=0.492)$ and one case of erectile dysfunction $(P=1.000)$ in IIA sacrifice group, while they were not seen in IIA salvage group. There was no ruptured iliac access, device-related malfunction, spinal cord ischemia or bowel ischemia in either group.

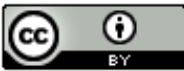

(C) The Author(s) 2020. Open Access This article is licensed under a Creative Commons Attribution 4.0 International License (https://creativecommons.org/licenses/by/4.0/), which permits unrestricted use sharing, adaptation, distribution and reproduction in any medium or format, for any purpose, even commercially, as long as you give appropriate credit to the original author(s) and the source, provide a link to the Creative Commons license, and indicate if changes were made.

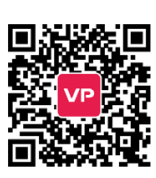


Conclusion: We found coverage of IIA aneurysmal extension during EVAR of AAA to be technically feasible and safe.

Keywords: Abdominal aortic aneurysm, lliac artery aneurysm, endovascular abdominal aortic aneurysm repair, clinical outcomes

\section{INTRODUCTION}

Endovascular aneurysm repair (EVAR) has become progressively common in abdominal aortic aneurysm (AAA) repair. Concomitant aneurysm of the common iliac arteries (CIAs) is seen in around one-third of AAA patients ${ }^{[1,2]}$. Internal iliac artery (IIA) embolization and extension of the endograft limb into the external iliac artery (EIA) can widen the indications for EVAR. However, the endovascular repairs of abdominal aortic aneurysms in patients with aneurysmal extensions to the iliac bifurcation could be associated with higher complications and/or secondary procedures ${ }^{[3]}$.

The optimal endovascular management of the IIA occlusion in aortoiliac aneurysms is controversial. Unilateral occlusion of IIA is relatively safe, but bilateral IIA occlusion could be associated with complications, such as ischemic colitis or neurologic impairment. Therefore, revascularization of at least one of the hypogastric flows might be necessary to maintain pelvic perfusion where the stent-grafts are extended into the bilateral EIAs ${ }^{[1,4]}$. Different techniques are utilized to preserve IIA patency; however, most surgical procedures are limited by the increased cost, contrast use and operative time leading to unnecessary radiation exposure ${ }^{[5]}$. Therefore, in this study, we aimed to assess the operative outcomes of IIA coverage during EVAR in our tertiary vascular referral center.

\section{METHODS}

This is a retrospective observational study of patients who had elective EVAR from 2002 to 2018 in our tertiary vascular referral center. The study was approved by our Institutional Research Ethics Committee. All patients were identified from our medical records and any missing data were obtained from the institutional patient administration system, and archiving of the picture and communication system. We excluded patients with ruptured AAA, aortoiliac occlusive disease and focal abdominal dissection.

Postoperative complications are reported based on the Society for Vascular Surgery reporting guidelines ${ }^{[6]}$.

\section{Outcomes}

Primary outcomes included 30-day mortality and overall survival. Secondary outcomes included freedom from reintervention, aneurysm-related survival and complication rates (new-onset buttock claudication, erectile dysfunction and intestinal ischemia).

Following discharge, follow-up was performed with physical examination and aortic computed tomography angiography (CTA) at six weeks and duplex ultrasound (DUS) imaging at six and twelve months in the first year and annually after that. In selective patients, repeat control CTA was performed if there was evidence of sac expansion and/or endoleak in DUS.

\section{Operative procedures}

All patients underwent surgery under general anesthesia. Different stent-grafts were used: AneuRx, Talent, Endurant and Endurant II (Medtronic, Santa Rosa, Calif); Excluder (W.L. Gore \& Associates, Flagstaff, Ariz); and Powerlink, AFX and AFX 2 (Endologix, Irvine, Calif). Endograft selection was made based on the preference of the surgeon and vascular anatomy. An iliac limb $\geq 20 \mathrm{~mm}$ in distal diameter was considered as a flared limb (FL). The FL extensions were chosen from large-diameter iliac extension limbs with range of 20-28 $\mathrm{mm}$. 
Table 1. Baseline characteristics of the patients

\begin{tabular}{lllc}
\hline & IIA salvage group $(\boldsymbol{n}=\mathbf{3 2})$ & IIA sacrifice group $(\boldsymbol{n}=\mathbf{3 3})$ & $\boldsymbol{P}$ value \\
\hline Male, $\boldsymbol{n}$ (\%) & $19(59.38 \%)$ & $25(75.76 \%)$ & 0.191 \\
Mean age (years, SD) & $78 \pm 10$ & $78 \pm 13$ & 1 \\
Hypertensive & 22 & 22 & 1 \\
Hyperlipidemia & 15 & 19 & 0.46 \\
Diabetes Mellitus & 2 & 6 & 0.258 \\
Ischemic Heart Disease & 20 & 14 & 0.138 \\
Peripheral Arterial Disease & 8 & 4 & 0.215 \\
Carotid Artery Disease & 4 & 2 & 0.427 \\
Respiratory Disorder & 21 & 22 & 1 \\
Renal Disorder & 0 & 2 & 0.492 \\
Smokers & 20 & 27 & 0.102 \\
\hline
\end{tabular}

IIA: internal iliac artery; SD: standard deviation

Embolization was performed for IIA aneurysm and/or IIA originating from CIA aneurysm. The proximal trunk of IIA was embolized, leaving the branches for collateral formation. We used mainly the contralateral approach for IIA embolization. First, we embolized with coils (MR Eye or Nestor Coils, Cook Medical) at the main IIA orifice before it bifurcates into the anterior and posterior division to achieve IIA occlusion. Then, we inserted the Amplatzer ${ }^{\mathrm{TM}}$ vascular plug to close the door. The coils were tightly packed. The overall aim was to maintain the collateral passageway between the anterior and posterior open.

\section{Data analysis}

Baseline demographics, preoperative features, surgical details and postoperative complications were noted. Aneurysm morphology and maximum diameter was recorded after analyzing the preoperative and followup CTAs. Concomitant common iliac artery aneurysm (CCIAA) was defined as $>20 \mathrm{~mm}$ maximum outer wall-to-outer wall CIA diameter.

Statistical Package for the Social Sciences (SPSS) version 23 (IBM, Armonk, NY, USA) was used for statistical analysis. Chi-square tests (or Fisher's exact test based on distribution) for discrete variables and Student $t$-tests (or Mann-Whitney $U$ test) for continuous variables were used for comparative analysis. A $P$-value $<0.05$ was considered statistically significant. Sustained clinical and hemodynamic improvement, freedom from binary restenosis and re-intervention, amputation-free survival and overall survival were estimated using the Kaplan-Meier survival analysis on a per-patient basis.

\section{RESULTS}

From 2002 to 2018, 540 patients underwent EVAR for AAA in our center. Sixty-five $(12.04 \%, n=65 / 540)$ had iliac aneurysm extension. Among these 65 cases, the IIA was not covered in 32 patients (IIA salvage/ spared group), while they were covered in 33 patients (IIA sacrifice group). The IIA sacrifice group consisted of 25 unilateral and eight bilateral coverages.

The baseline patient characteristics are detailed in Table 1. More male patients were in the IIA sacrifice group than the IIA salvage group $(75.76 \% v s .59 .38 \%, P=0.191)$, while the ages of patients were similar ( 78 \pm 13 years $v s .78 \pm 10$ years, $P=1.000)$. No statistically significant differences in baseline demographics, risk factors and clinical presentations were observed.

The mean AAA diameter was slightly larger in the IIA sacrifice group than the IIA salvage group but not significant $(5.70 \pm 2.50 \mathrm{~cm} v s .5 .40 \pm 1.65 \mathrm{~cm}, P=0.569)$. However, there were significant differences in the right CIA diameter $(32.90 \pm 20.98 \mathrm{~mm} v s .15 .40 \pm 9.24 \mathrm{~mm}, P=0.001)$ and right IIA diameter $(16.40 \pm 9.40 \mathrm{~mm}$ vs. $9.00 \pm 2.30 \mathrm{~mm}, P=0.001)$ between the IIA sacrifice and IIA salvage groups [Table 2]. 
Table 2. Procedural and anatomical features

\begin{tabular}{lccc}
\hline & IIA salvage group $(\boldsymbol{n}=\mathbf{3 2})$ (Mean \pm SD) & IIA sacrifice group $(\boldsymbol{n}=\mathbf{3 3})$ (Mean \pm SD) & $\boldsymbol{P}$ value \\
\hline Operative time $(\mathrm{h})$ & $2.20 \pm 0.44$ & $3.43 \pm 1.54$ & $0.001^{\star}$ \\
Aneurysm size $(\mathrm{cm})$ & $5.40 \pm 1.65$ & $5.70 \pm 2.50$ & 0.569 \\
Right CIA diameter (mm) & $15.40 \pm 9.24$ & $32.90 \pm 20.98$ & $0.001^{\star}$ \\
Left CIA diameter (mm) & $18.95 \pm 4.77$ & $16.82 \pm 6.52$ & 0.137 \\
Right IIA diameter (mm) & $9.00 \pm 2.30$ & $16.40 \pm 9.40$ & $0.001^{\star}$ \\
Left IIA diameter (mm) & $9.10 \pm 2.80$ & $11.48 \pm 6.80$ & 0.071 \\
HDU stay (days) & $0.16 \pm 0.57$ & $0.75 \pm 1.49$ & $0.040^{\star}$ \\
Total hospital stay (days) & $2.91 \pm 2.67$ & $5.56 \pm 4.88$ & $0.005^{\star}$ \\
\hline
\end{tabular}

*Statistically significant. IIA: internal iliac artery; SD: standard deviation; CIA: common iliac artery; HDU: high density unit

Table 3. Postoperative complications

\begin{tabular}{lccc}
\hline Complications & IIA salvage group $(\boldsymbol{n}=\mathbf{3 2})$ & IIA sacrifice group $(\boldsymbol{n}=\mathbf{3 3})$ & $\boldsymbol{P}$-value \\
\hline Thirty-day mortality & 0 & 0 & - \\
Hematoma & 1 & 3 & 0.613 \\
Infection & 1 & 1 & 1 \\
Cardiac complications & 1 & 4 & 0.355 \\
Respiratory complications & 0 & 2 & 0.492 \\
Renal complications & 0 & 1 & 1 \\
Type lb endoleak & 0 & 3 & 0.238 \\
Lower limb macro-embolization & 0 & 2 & 0.492 \\
Buttock claudication & 0 & 1 & 1 \\
Erectile dysfunction & 0 & 1 & 1 \\
Stroke & 0 & 0 & - \\
Bowel ischemia & 0 & 0 & - \\
Spinal cord ischemia & 0 & 0 & - \\
Deep vein thrombosis & 0 & 0 & - \\
Pulmonary embolism & 0 & 0 & - \\
\hline
\end{tabular}

IIA: internal iliac artery

The IIA sacrifice group compared to the IIA salvage group had significantly higher procedure time ( $3.43 \pm$ $1.54 \mathrm{~h}$ vs. $2.20 \pm 0.44 \mathrm{~h}, P=0.001)$, mean hospital stay (5.56 \pm 4.88 days $v s .2 .91 \pm 2.67$ days, $P=0.005)$ and high dependency unit (HDU) stay $(0.75 \pm 1.49$ days $v s .0 .16 \pm 0.57$ days, $P=0.040)$.

Technical success was $100 \%$, and there was no 30-day mortality in either group. The IIA sacrifice group had more postoperative complications in general when compared to the IIA salvage group, but they were not significant $(P<0.05)$ [Table 3]. As such, there were higher numbers of hematoma $(3$ vs. $1, P=$ $0.613)$, cardiac complications ( 4 vs. $1, P=0.355)$, respiratory complications $(2$ vs. $0, P=0.492)$ and renal complications ( 1 vs. $0, P=1.000)$ in the IIA sacrifice group. Similarly, IIA sacrifice group had two cases of lower limb microembolization $(P=0.492)$, one erectile dysfunction $(P=1.000)$, and one buttock claudication $(P=1.000)$, while they were not seen in IIA salvage group. The buttock claudication occurred in a patient with bilateral IIA coverage. There was no ruptured iliac access, device-related malfunction, spinal cord ischemia or bowel ischemia in either group.

The mean follow-up was 3.28 years. At three-years, there were no statistically significant difference in the freedom from reintervention $(85 \% v s .93 .75 \%, P=0.253)$ [Figure 1], aneurysm-related survival ( $97 \% v s$. $97 \%, P=0.982)$ [Figure 2] and overall survival $(67 \%$ vs. $72 \%, P=0.963)$ [Figure 3] between the IIA sacrifice and IIA sparing groups.

\section{DISCUSSION}

EVAR is progressively being adopted in AAA repair. Many reports focus on the proximal landing zones; however, there could be a need to extend EVAR to EIA due to either short CIA or aneurysmal CIAs. Recent 


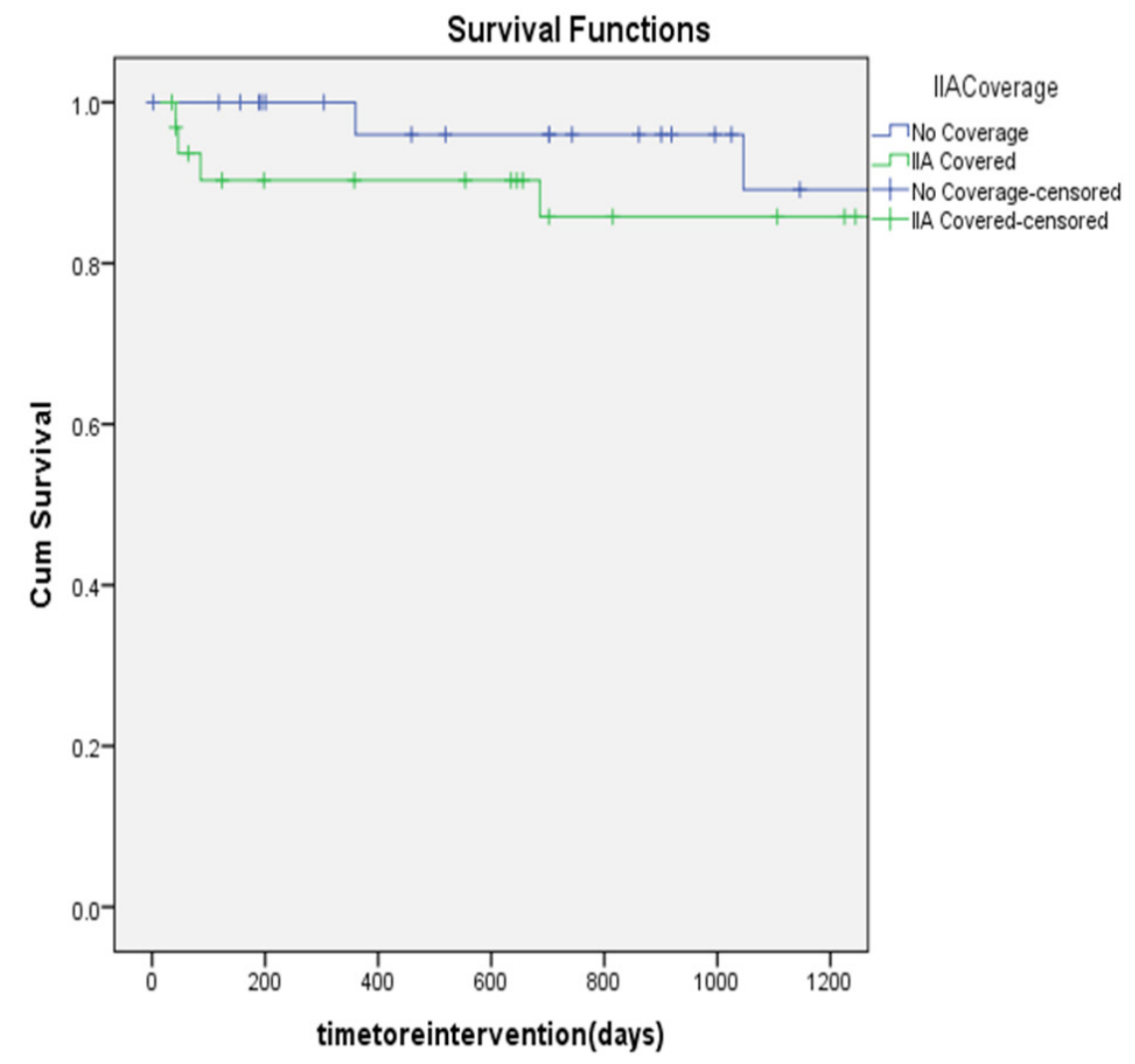

Figure 1. Three-year freedom from re-intervention

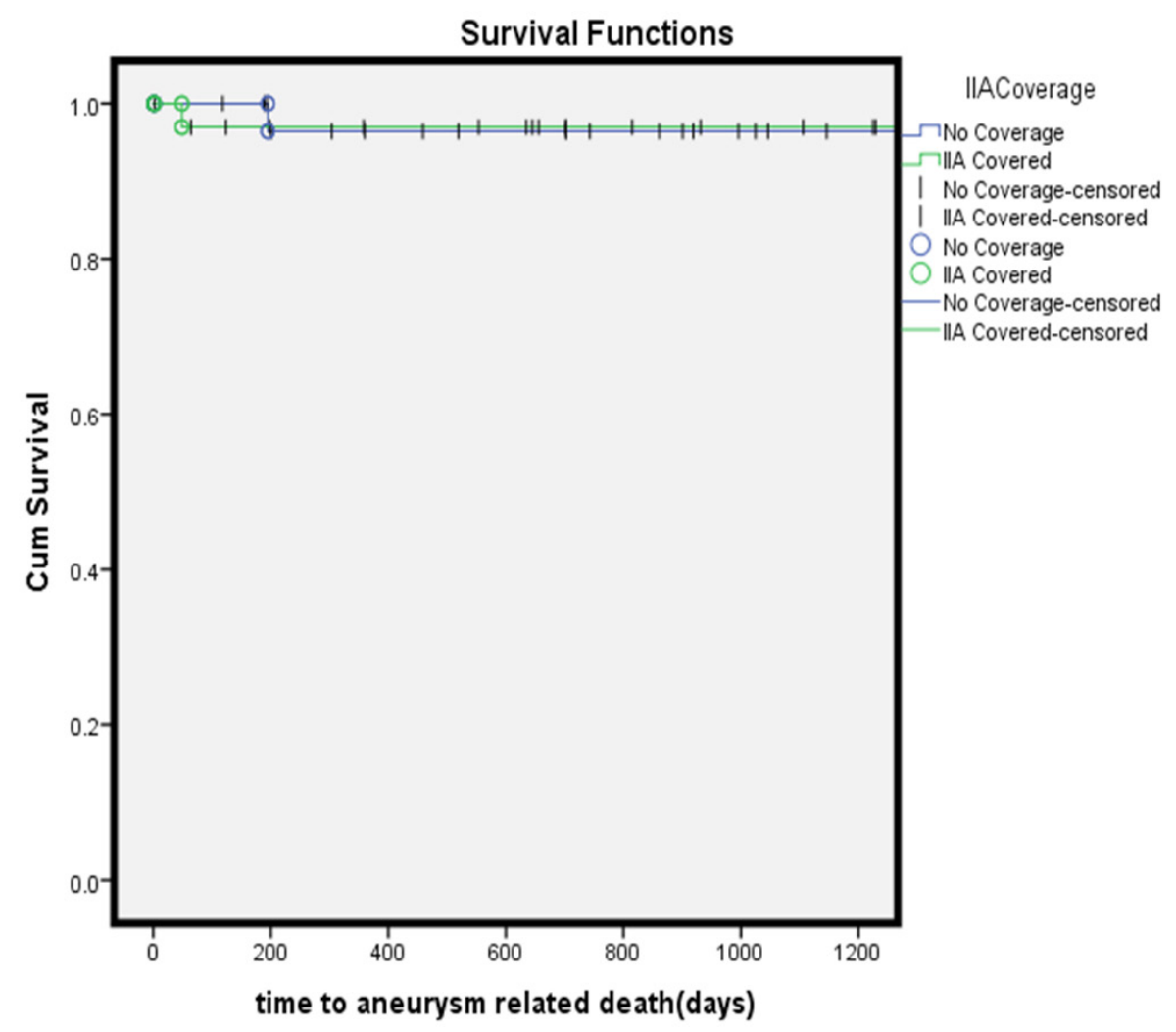

Figure 2. Three-year aneurysm-related survival 


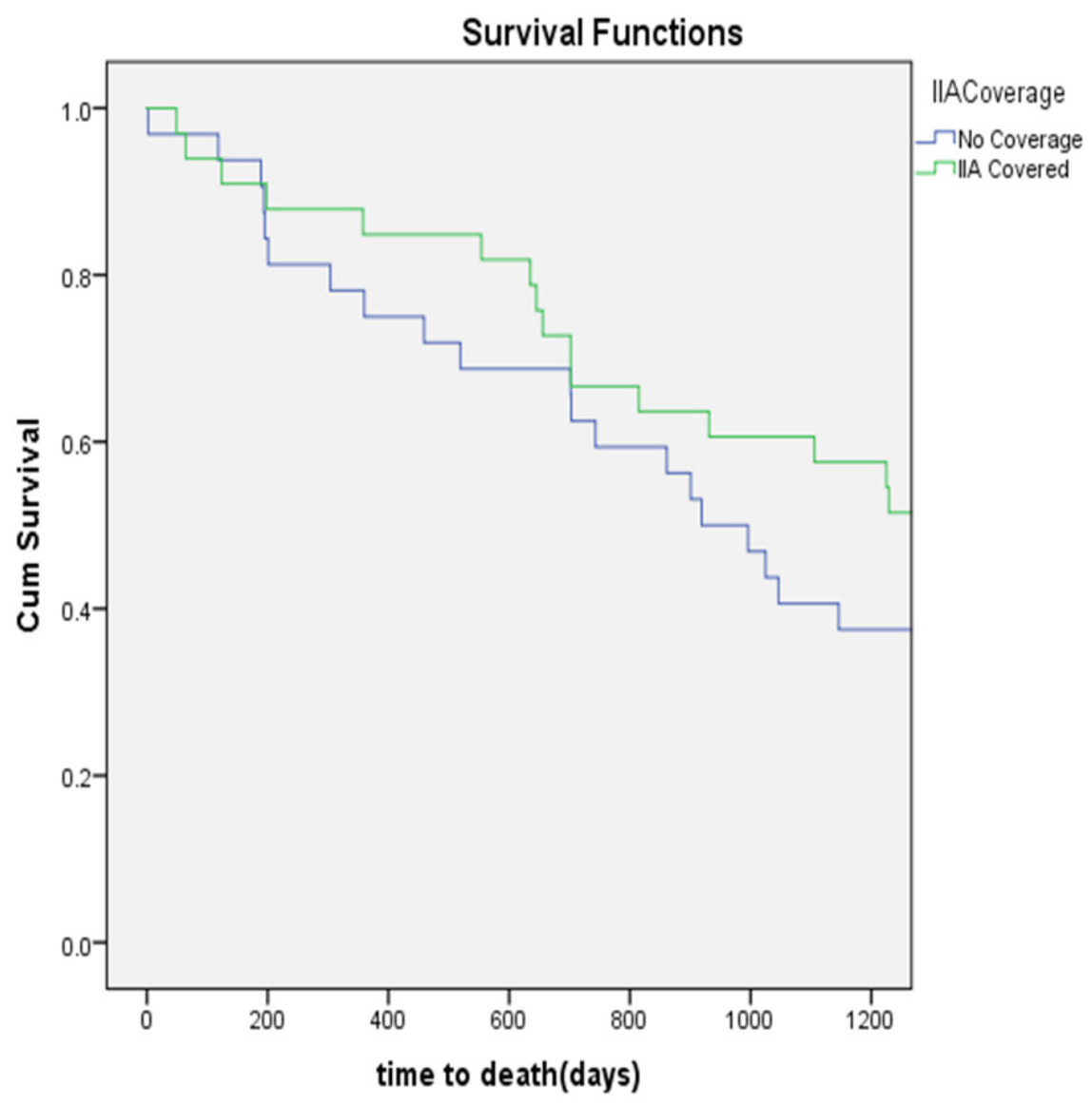

Figure 3. Overall survival at three years

guidelines recommend preserving at least one IIA to maintain the circulation of the pelvis to avoid buttock claudication and bowel ischemia ${ }^{[7]}$.

The options of preserving IIA include the FL, which can accommodate up to $25 \mathrm{~mm}$ CIA; iliac branched devices (IBD); and EIA to IIA bypass either surgically or by endovascular means. Unfortunately, all of these solutions are associated with significant operation time and contrast amount ${ }^{[8]}$. In addition, the FL technique could be linked with a high rate of dilatation with Type Ib endoleak, five times more than the corresponding less than $20 \mathrm{~mm}$ CIA diameter ${ }^{[9]}$. Additionally, the difficulty in later usage of IBD necessitates the usage of trans-axillary access with increased risk of stroke ${ }^{[9,10]}$.

Anatomical limitations prohibit the usage of IBD in many iliac aneurysms as IBD necessitates certain anatomical features that are only applicable in $40 \%$ of CIA aneurysmal anatomy ${ }^{[8]}$. Additionally, added financial burden should be taken into account when treating AAA, particularly when compared to the open surgery ${ }^{[8,11-14]}$. Similarly, these newer IBD devices have limited evidence on long-term outcomes. Furthermore, the high cost and longer procedure time, absence of the extended follow-up outcomes and poor quality of life may hinder the application of IBD in AAA treatment ${ }^{[14-17]}$.

The surgical option to revascularize the IIA can also increase the complexity and morbidity of the EVAR. Despite being effective in flow preservation, repositioning of IIA could increase the morbidity and recovery time, increasing the risk of ureteric and venous injuries, primarily in obese patients with IIA aneurysm ${ }^{[8,18]}$. 
Contrary, multiple reports showed that coverage of the IIA could be tolerated without devastating complications. Buttock claudication, the most common complications, is likely reversible after a short period with persistent buttock claudication in less than half of patients. Similarly, reports of the devastating complications, bowel and spinal cord ischemia, seem to be exaggerated and true occurrence seem to be exceedingly rare in the literature ${ }^{[13,17,19,20]}$.

Mehta et al. ${ }^{[21]}$ reported that the innocence of bilateral IIA coverage and the selective sacrifice of one or both hypogastric arteries could be done safely during EVAR, even in patients with challenging anatomy. Based on them, associated comorbidities, such as shock, distal embolization or inability to salvage collateral branches from the EIA and femoral arteries, may have contributed to the increased morbidity in the previous IIA interruption reports ${ }^{[21]}$.

Additionally, surgical ligation of one or both IIAs is occasionally needed, for instance in renal transplantation, and life-threatening conditions such as gynecological emergencies have been performed without adverse effects. Iliopoulos et al. ${ }^{[22]}$ studied the circulation of IIA during various open aortoiliac surgeries and found that the ipsilateral EIA branches and common femoral arteries contribute to IIA circulation more than the contralateral IIA. This was proved in the acute setting, and it is likely to be right in the long term ${ }^{[22]}$.

Furthermore, the preservation of the superior-inferior gluteal system is crucial for the pelvic viscera to maintain the collateral circulation from the ipsilateral deep femoral artery via the inferior gluteal artery and prevent buttock claudication. Fujioka et al. ${ }^{[23]}$ recommended that deep femoral arterioplasty during EVAR may be needed in those with an advanced stenotic lesion at its origin as a valuable means to decrease buttock claudication following the IIA occlusion.

In the current study, we tried hard to preserve the IIA if there was a sufficient landing zone. In those cases where we covered one or two IIAs, there were no significant differences in complications. There was no bowel ischemia and spinal cord ischemia in either group; however, there was one patient who suffered buttock claudication in the IIA coverage group.

Data about buttock claudication should be analyzed cautiously as most of the studies are not comprehensive and do not objectively assess the symptoms ${ }^{[13,17,24]}$. Fujioka et al. ${ }^{[23]}$ reported no buttock claudication in their study with 71 patients following the embolization of the IIA proximally and two weeks before the EVAR, allowing the collateral to form properly. Based on the study by Bosanquet et al ${ }^{[17]}$, catastrophic ischemic events such as gluteal, bowel and spinal ischemia are rare $(<1 \%)$, and the actual rate rates could be less than those reported. In their systematic analysis ${ }^{[17]}$, they showed a clear reduction in reporting of these complications in papers published before 2007 (3.6\%) compared to those published after $2007(0.9 \%)(P$ $<0.001)$. The reasons could be multifactorial, such as increased plugs use, a greater understanding of the IIA circulation, and enhanced operator experience ${ }^{[13,17,23]}$. Additionally, the etiology and assessment of these reported complications may be complicated as the majority of the patients were of advanced age with common comorbidities, such as diabetes ${ }^{[8,17,25,26]}$.

In our case, the procedure time, HDU stay and total hospital stay were significantly higher in the IIA sacrifice group compared to the IIA salvage group. However, there was no statistically significant difference in the postoperative complications from sacrificing IIAs.

\section{Study limitations}

Our study is a retrospective study, and we were limited to a small number of patients. Similarly, we did not use IBD in our patients. The usage of IBD could be jeopardized by the diameter of IIAs, as there was a 
statistically significant higher size of IIA in the IIA sacrifice group. We did not perform quality of life and subgroup analysis with unilateral and bilateral IIA coverage. Furthermore, the lack of standardized way to assess erectile dysfunction and buttock claudication might be responsible for the lower erectile dysfunction and buttock claudication mentioned in the current study.

In conclusion, Although the IIA sacrifice group had higher total hospital and high dependency unit stay, there were no significant differences in postoperative complications, three-year freedom from reintervention and aneurysm-related as well as overall survival. Based on our experience, the coverage of IIA aneurysmal extension during endovascular repair of the aortoiliac aneurysmal disease seems technically feasible and safe.

\section{DECLARATIONS}

\section{Authors' contributions}

Concept and design: Ghoneim B, Tawfick W, Sultan S

Analysis and interpretation, writing the article, critical revision and final approval of the article, overall responsibility: Ghoneim B, Canning P, Acharya Y, Hynes N, Tawfick W, Sultan S

Data collection: Ghoneim B, Canning P, Acharya Y

Statistical analysis: Ghoneim B, Canning P, Acharya Y, Tawfick W

\section{Availability of data and materials}

Not applicable.

\section{Financial support and sponsorship}

None.

\section{Conflicts of interest}

All authors declared that there are no conflicts of interest.

\section{Ethical approval and consent to participate}

The study is approved by the Galway Clinical Research Ethics Committee (C.A. 1210, 13/02/2015).

\section{Consent for publication}

Not applicable.

\section{Copyright}

(c) The Author(s) 2020.

\section{REFERENCES}

1. Hosaka A, Kato M, Kato I, Isshiki S, Okubo N. Outcome after concomitant unilateral embolization of the internal iliac artery and contralateral external-to-internal iliac artery bypass grafting during endovascular aneurysm repair. J Vasc Surg 2011;54:960-4.

2. Armon M, Wenham P, Whitaker S, Gregson R, Hopkinson B. Common iliac artery aneurysms in patients with abdominal aortic aneurysms. Eur J Vasc Endovasc Surg 1998;15:255-7.

3. Albertini JN, Favre JP, Bouziane Z, Haase C, Nourrissat G, Barral X. Aneurysmal extension to the iliac bifurcation increases the risk of complications and secondary procedures after endovascular repair of abdominal aortic aneurysms. Ann Vasc Surg 2010;24:663-9.

4. Lee WA, Nelson PR, Berceli SA, Seeger JM, Huber TS. Outcome after hypogastric artery bypass and embolization during endovascular aneurysm repair. J Vasc Surg 2006;44:1162-8; discussion 1168-9.

5. Machado RM, Rego DN, de Oliveira PNFP, de Almeida RMGF. Endovascular treatment of internal iliac artery aneurysms: single center experience. Braz J Cardiovasc Surg 2016;31:127-31.

6. Chaikof EL, Blankensteijn JD, Harris PL, et al; Ad Hoc Committee for Standardized Reporting Practices in Vascular Surgery of The Society for Vascular Surgery/American Association for Vascular Surgery. Reporting standards for endovascular aortic aneurysm repair. $J$ Vasc Surg 2002;35:1048-60. 
7. Chaikof EL, Dalman RL, Eskandari MK, et al. The society for vascular surgery practice guidelines on the care of patients with an abdominal aortic aneurysm. J Vasc Surg 2018;67:2-77.e2.

8. Ghosh J, Murray D, Paravastu S, Farquharson F, Walker MG, Serracino-Inglott F. Contemporary management of aorto-iliac aneurysms in the endovascular era. Eur J Vasc Endovasc Surg 2009;37:182-8.

9. Gray D, Shahverdyan R, Reifferscheid V, Gawenda M, Brunkwall JS. EVAR with flared iliac limbs has a high risk of late type 1b endoleak. Eur J Vasc Endovasc Surg 2017;54:170-6.

10. Bannazadeh M, Jenkins C, Forsyth A, et al. Outcomes for concomitant common iliac artery aneurysms after endovascular abdominal aortic aneurysm repair. J Vasc Surg 2017;66:1390-7.

11. Loth AG, Rouhani G, Gafoor SA, Sievert H, Stelter WJ. Treatment of iliac artery bifurcation aneurysms with the second-generation straight iliac bifurcated device. J Vasc Surg 2015;62:1168-75.

12. Gray D, Shahverdyan R, Jakobs C, Brunkwall J, Gawenda M. Endovascular aneurysm repair of aortoiliac aneurysms with an iliac sidebranched stent graft: studying the morphological applicability of the Cook device. Eur J Vasc Endovasc Surg 2015;49:283-8.

13. Kouvelos GN, Katsargyris A, Antoniou GA, Oikonomou K, Verhoeven EL. Outcome after interruption or preservation of internal iliac artery flow during endovascular repair of abdominal aorto-iliac aneurysms. Eur J Vasc Endovasc Surg 2016;52:621-34.

14. Marques de Marino P, Botos B, Kouvelos G, Verhoeven ELG, Katsargyris A. Use of bilateral cook zenith iliac branch devices to preserve internal iliac artery flow during endovascular aneurysm repair. Eur J Vasc Endovasc Surg 2019;57:213-9.

15. Donas KP, Inchingolo M, Cao P, et al; pELVIS Registry collaborators, Martin Austermann; Kristin Weiss; Michel Bosiers; Matteo Barbante; Gioele Simonte; Aaron Fargion and Fabrizio Masciello. Secondary procedures following iliac branch device treatment of aneurysms involving the iliac bifurcation: the pELVIS registry. J Endovasc Ther 2017;24:405-10.

16. Farivar BS, Abbasi MN, Dias AP, et al. Durability of iliac artery preservation associated with endovascular repair of infrarenal aortoiliac aneurysms. J Vasc Surg 2017;66:1028-36.e18.

17. Bosanquet DC, Wilcox C, Whitehurst L, Cox A, Williams IM, Twine CP; British Society of Endovascular therapy (BSET). Systematic review and meta-analysis of the effect of internal iliac artery exclusion for patients undergoing EVAR. Eur J Vasc Endovasc Surg 2017;53:534-48.

18. Fatima J, Correa MP, Mendes BC, Oderich GS. Pelvic revascularization during endovascular aortic aneurysm repair. Perspect Vasc Surg Endovasc Ther 2012;24:55-62.

19. Libicher M, Pavlidis D, Bangard C, Gawenda M. Occlusion of the internal iliac artery prior EVAR: comparison of coils and plugs. Vasc Endovascular Surg 2012;46:34-9.

20. Mansour W, Capoccia L, Sirignano P, et al. Clinical and functional impact of hypogastric artery exclusion during EVAR. Vasc Endovascular Surg 2016;50:484-90.

21. Mehta M, Veith FJ, Ohki T, et al. Unilateral and bilateral hypogastric artery interruption during aortoiliac aneurysm repair in 154 patients: a relatively innocuous procedure. J Vasc Surg 2001;33:S27-32.

22. Iliopoulos JI, Hermreck AS, Thomas JH, Pierce GE. Hemodynamics of the hypogastric arterial circulation. J Vasc Surg 1989;9:637-41; discussion 641-2.

23. Fujioka S, Hosaka S, Morimura H, et al. Outcomes of extended endovascular aortic repair for aorto-iliac aneurysm with internal iliac artery occlusion. Ann Vasc Dis 2017;10:359-63.

24. Kontopodis N, Tavlas E, Papadopoulos G, Galanakis N, Tsetis D, Ioannou CV. Embolization or simple coverage to exclude the internal iliac artery during endovascular repair of aortoiliac aneurysms? Systematic review and meta-analysis of comparative studies. $J$ Endovasc Ther 2017;24:47-56.

25. Bharwani N, Raja J, Choke E, et al. Is internal iliac artery embolization essential prior to endovascular repair of aortoiliac aneurysms? Cardiovasc Intervent Radiol 2008;31:504-8.

26. Chun JY, Mailli L, Abbasi MA, et al. Embolization of the internal iliac artery before EVAR: is it effective? Is it safe? Which technique should be used? Cardiovasc Intervent Radiol 2014;37:329-36. 